\title{
Peaked Interest: Public Interest in Hunger and the Economic Cycle
}

\author{
Dan Farhat \\ Radford University
}

\author{
Danylle R. Kunkel \\ Radford University
}

Jessie Quesenberry

Radford University

\begin{abstract}
United Nations Sustainable Development Goal \#2 is to end hunger. Private enterprises can aid in this effort if they have the right information. This paper creates an index to measure general interest in hunger in the United States (2004-2018). This 'hunger interest index' is based on keyword search frequency data from Google for a variety of hunger related keywords which appear in the mission statements of social businesses. We compare the 'hunger interest index' to broader economic trends and find that general interest in hunger increases as economic misery increases. Further, interest in hunger is shown to be positively related to interest in food banks and donations. The results provide valuable information to social enterprises for which combating hunger is a key value, and to social entrepreneurs looking to focus on hunger reduction in their new venture.
\end{abstract}

Keywords: SGD's, Google Trends, Hunger Interest Index, Social Business

\section{INTRODUCTION}

Hunger is a global problem. At the 2015 UN Sustainable Development Summit, the United Nations made it a goal to 'end hunger, achieve food security and improved nutrition, and promote sustainable agriculture' (Sustainable Development Goal \#2 [SDG2]). National governments, non-profit organizations and select international agencies are the typical players responsible for achieving a goal like this. However, private business may also be of use. For-profit social enterprises with missions and values associated with hunger reduction are increasing in popularity. These 'hunger-based' businesses contribute a share of their profits to activities which reduce malnutrition and food insecurity, thus helping to achieve SDG2. Like any regular for-profit enterprise, a lucrative hunger-based social business cares about serving their customers. The number of potential customers interested in eliminating hunger affects this sort of firm's sales (and thus their efforts towards SDG2). Evaluating changes in the public's interest in hungerrelated issues is therefore useful in the strategic decision-making processes of hunger-based enterprises.

There is however a connection between the state of the economy and hunger-reduction efforts taken on by for-profit social enterprises to account for. In general, aggregate consumption spending tends to fall 
in the face of growing unemployment, increased inflation, and decreased wages (Mansoor, 2011). This is also the case for food spending specifically. Birkenmaier, Huang, \& Kim (2016) discovered that household food insecurity is largely influenced by the income, employment status, and type of employment of the individuals within the household. During recessionary periods, there is growing unemployment and decreasing wages which affects the ability of a household to purchase food. Von Braun (2008) notes that the 2008 financial crises caused inflation in food prices despite deflation in the greater economy. At higher prices, households can afford even less nutrition. All-in-all, we can expect a greater need to combat the problem of hunger during recessionary periods. Households turn to resources like food banks, charities and governmental programs, like the Supplemental Nutrition Assistance Program (SNAP), to ensure their household nutritional needs are met.

The impact on consumer spending makes recessionary periods a tough time for businesses. Many firms, including social enterprises, have difficulty maintaining sales during an economic downturn. Revenues are reduced and profit margins can be slim. This poses a catch-22 situation for hunger-based for-profit firms. A hunger-based social business has an opportunity for increased exposure during a recession. Issues related to hunger become more prevalent and the firm's marketing message is more influential. However, finding willing customers with the available resources to make purchases during an economic slow-down is more difficult. In the end, this firm may not be financially able to make substantial efforts in hunger reduction when it is most needed due to a shrinking revenue stream.

In this study, we focus on evaluating public interest in social businesses connected to hunger and food insecurity. We first create a 'hunger interest index' (or HII) using keyword search data from Google. The keywords we use are taken from the mission statements of hunger-related B Corporations (businesses with a social/environmental agenda). As a result, the HII connects directly to the marketing messages shared by these types of organizations and can therefore inform decision-making. We identify trends in this index, but these trends are of limited use to management choices without accounting for broad changes in the economy. We compare movements in the HII to a similar index of economic performance. We illustrate how this information improves decision-making at the end of this study.

In the remainder of this paper, we review previous literature related to the key aspects of our study. This includes methods of predicting charitable behaviors, the B Corporation certification, the UN Strategic Development Goal (SDG) paradigm, and the power of using keyword search data (Google Trends). We describe the methodology we use to create the HII and a similar index that represents the overall economic state. We perform a series of simple comparative analyses and draw some conclusions about the relationship between the HII and the state of the economy. Finally, we illustrate the practical use of our findings. A short conclusion synthesizes the main message.

\section{PREVIOUS LITERATURE}

\section{Predictors, Barriers, and Importance of Donations}

There are many different reasons why people donate money to charitable organizations. Bekkers and Wiepking (2011) defined 8 forces that drive a person to donate: awareness of need, solicitation, costs and benefits, altruism, reputation, psychological benefits, values, and efficacy. Altruism can be split further into two categories of pure altruism and impure altruism. Pure altruism occurs when people care about society and then are motivated to donate, while impure altruism happens when people gain happiness from the act of giving money to charity (Cappellari, Ghinetti, \& Turati, 2011). Smith and McSweeney (2007) found that a person's income, education, and religious affiliation also are predictors of donation behavior. Two other predictors of donations include gender and relationship status (single versus married) (Mesch, Brown, Moore, \& Hayat, 2011). Women give more than men and view donations as exhibiting their moral beliefs, while men donate due to social expectation pressures (Mesch et al., 2011). Married couples give more and are more likely to give than single individuals (Mesch et al., 2011).

People donate to organizations when they believe that the money will be effectively used. Two major barriers to receiving donations are how long the organization has been operating (new organizations seem riskier when compared to established organizations) and its respective reputation within the community (a 
bad reputation casts doubt on the organizations potential for success) (Posnett \& Sandler, 1989). Trussel and Parsons (2007) propose that efficiency, stability, and information available to the public affects donations. 'Efficiency' is the level that nonprofits use their resources to achieve their mission. 'Stability' is the nonprofit's ability to continue operating if resources become constrained. The information a nonprofit makes available to the public includes things like their mission, how they operate, how the donations would be used, etc. Nonprofits that inefficiently use their resources, are unstable, and provide little information to the public are unlikely to obtain much funding.

Often, donations are the main source of income for nonprofits ${ }^{1}$ and charitable organizations (Abreu, Laureano, da Silva, Dionísio, \& Alwi, 2013). When the revenue sources decrease, organizations can help less people or are forced to shut down due to the lack of money. The literature on charitable giving shows how nonprofit organizations and charities are gaining access to information which can help them solicit potential donors with a greater chance of obtaining donations (Crosonm Handy \& Shang, 2009; Einolf, 2011; Bekkers, Weipking, 2011). Social businesses, however, perform some of the same activities as nonprofits and charities, but with an alternative source of income.

\section{B Corporations}

Social businesses have a dual-mission of making money and addressing social/environmental issues. The main difference between a social business and a charity is its ability to be financially self-sustaining to create a revenue stream through traditional business activities that is capable of funding operations and supporting a social/environmental mission at the same time (Saatci and Urper, 2013). These firms look at a double bottom-line (or a triple bottom-line) when measuring their success to capture both financial gain and positive social/environmental impact. There are several reasons why this business model is attractive to both firm owners and customers, many of which relate to a 'millennial' desire to make positive local and global contributions wherever possible (see e.g. Balch, 2017)

Some enterprises seek to verify or promote their status as a social business by obtaining credentials $b$ independent organizations. One such class of credentialed social enterprises are 'B corporations', which are certified by the nonprofit organization B Lab. B corporations are "businesses that meet the highest standards of verified social and environmental performance, public transparency, and legal accountability to balance profit and purpose" ("About B Corps", 2018). Businesses become certified B corporations because they are committed "to social and environmental causes...to prove that they are... genuine, authentic advocates of stakeholder benefits" and to "redefine the way people perceive success in the business world" (Kim, Karlesky, Myers, \& Schifeling, 2016, pg.4).

There are several B corporations interested in reducing hunger. One example is the natural food company Lycka in Germany. For every one of their food products sold, a fixed portion of the price goes directly to feeding and educating children in Burundi, Africa through a foundation that Lycka started ("Mission", 2019). Others include Link2Feed (Canada), Goodr (Atlanta, GA), Save on Meats (Canada), Cotswold Fayre (United Kingdom) and Good Food for Good Inc. (Canada).

\section{Sustainable Development Goals}

In 2015, the United Nations developed the 2030 Agenda for Sustainable Development, which encompasses the 17 Sustainable Development Goals (SDGs). The 17 SDGs build upon the 8 Millennium Development Goals that the UN hoped to achieve by 2015. The issues that the SDGs focus on ranges from improving human living conditions (SDGs 1-3 and 6), sustainably increasing economic growth (SDG 8), and improving the environmental condition of the earth (SDG 13-15). The SDGs encourage all member nations to engage in a global partnership to sustainably improve the lives of the residents.

The targets for achieving SDG 2 are to end hunger and malnutrition, to double the agricultural productivity of small-scale food producers, develop sustainable food systems, prevent trade restrictions in world agriculture markets, and ensure food commodity markets limit extreme food price volatility (UN, 2015). A study completed in 2015 assessed the ability of a typical developed country to complete each of the 17 SDGs. The SDGs were ranked on a scale of 1-8, with 1 representing goals that the country could complete with ease, and 8 representing SDGs that would be challenging for a country to complete. The 
study ranked SDG 2 as a 2.3 on the scale because many of the goal targets are more applicable in developing countries (Osborn, Cutter, \& Ullah, 2015). However, SDG 2 is one of the goals that both developed and developing countries need to achieve to ensure that the residents of the country can live healthy and productive lives.

According to the United Nations, 815 million people in the world today are undernourished, with an increase of 2 billion people expected to be undernourished by 2050 (UN,2015). Feeding America conducted research in 2017 that shows 40 million Americans struggle with hunger, with children accounting for 12 million of the 40 million ("Hunger in America", 2019). The same research from Feeding America also estimated that $58 \%$ of households within the United States that were food insecure used one of the national food programs which are: Supplemental Nutrition Assistance Program (SNAP), the National School Lunch Program, and the Special Supplemental Nutrition Program for Women, Infants, and Children (WIC) ("Hunger in America", 2019). Studies have found a direct relationship between the quantity and quality of food consumed by an individual and their "mental and physical health, psychosocial, behavioral, learning, family stress, and academic outcomes" (Sharkey, Dean, \& Nalty, 2013, pg. 2).

\section{Google Trends}

The internet has drastically changed the way people learn new information: if you need to know something, just search for it online. A way to evaluate what people are searching for now exists. Google has developed a tool called 'Google Trends' which collects data on the frequency of keyword searches made on Google's search engine. This data is presented as an index, with the period of greatest search volume set to 100 . We can look at the popularity of different keyword searches over time, and in different locations, to identify trends in interest. For example, figure 1 shows trends in searches for "food insecurity" in the United States (2004-2019). Note that searches for "food insecurity" have been increasing since 2013 and seem to follow a cyclical pattern.

FIGURE 1

“FOOD INSECURITY" KEYWORD SEARCHES IN GOOGLE TRENDS, 2004-2019

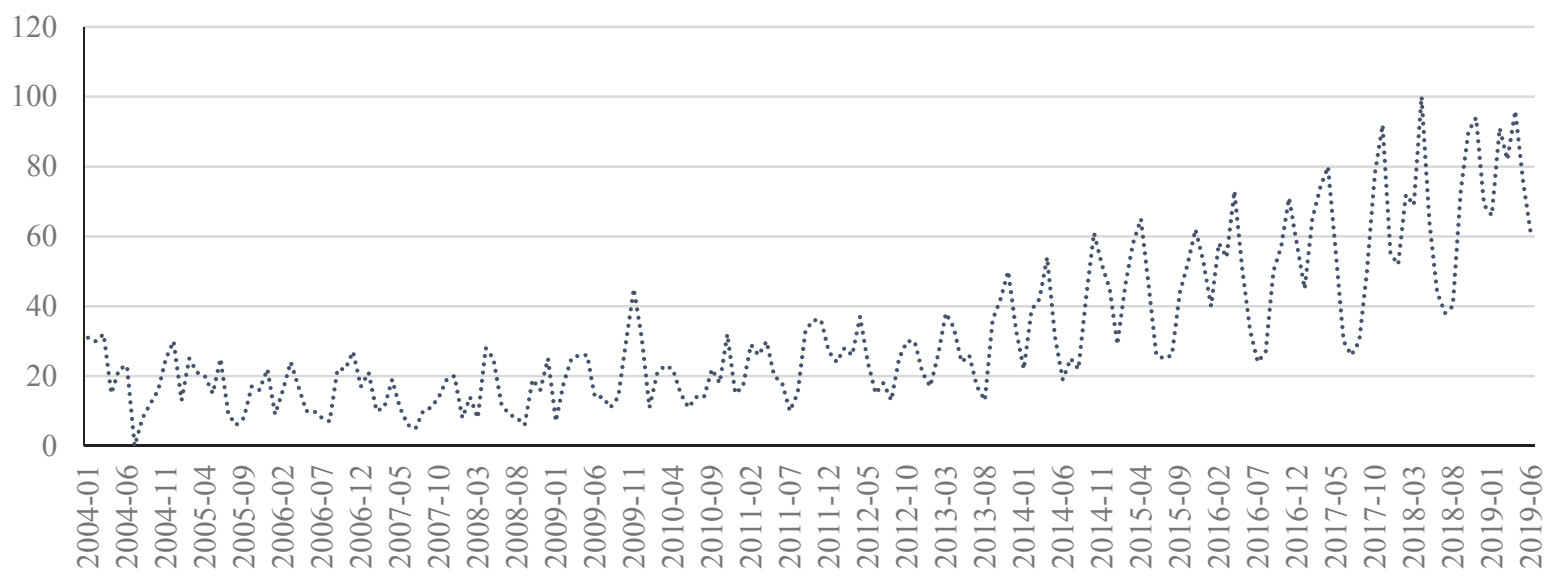

Google Trends data has been used in various forms of research from finding a relationship between the unemployment rate and sexually transmitted diseases (Farhat, 2017), to detect flu epidemics before the U.S. Centers for Disease Control and Prevention (CDC) is aware of the outbreak (Ginsberg, Mohebbi, Patel, Brammer, Smolinski, \& Brilliant, 2009), and to find a correlation between the state of the economy and an individual's mental health (Farhat \& Viitanen, 2017). Other uses for Google Trends include: forecasting the unemployment rate (Dilmaghani, 2019), surveillance of influenza outbreaks in South 
China (Kang, Zhong, He, Rutherford, \& Yang, 2013), and detecting Tuberculosis outbreaks (Zhou, Ye, \& Feng, 2011).

The application of Google Trends data can span disciplines and be used for data surveillance, causal inference, and to study the behavior of the population (Nuti, Wayda, Ranasinghe, Wang, Dreyer, Chen, \& Murugiah, 2014). As more individuals gain access to the internet, Google Trends data will continue to grow in value, providing an increasingly accurate reflection of the population's searches. Data gathered through Google Trends can be extremely useful for businesses who want to identify public interest for marketing purposes.

\section{METHODS AND RESULTS}

We can merge together information from B corporations with Google Trends. The data for this study began as a text analysis ${ }^{2}$ of high frequency words and phrases used in B corporation mission statements. The mission statements were pulled from the B Lab directory of B corporations. The set of high frequency words and phrases were then sorted into categories relating to all of the United Nation's 17 Sustainable Development Goals. For this study, we focus only on the words and phrases that pertain to the SDG 2 category. See table 1 for the terms used. This methodology ensures that the terms we use directly connect existing social businesses with the United Nation's objectives.

Data from Google Trends was extracted for each of the SDG 2 related terms. This data is monthly from January 2004 to October 2018. We used the Hodrick-Prescott (HP) filter to find a smooth trend within the data for each word. The smooth trend captures long-term changes in interest, much of which tends to be due to increasing internet usage. Short-term changes are more useful for immediate decisionmaking. We can identify the shorter-term cyclical patterns by extracting the long-term trend from the original data $($ cycle $=$ data - trend). For example, figure 2 illustrates the cyclical pattern for "food insecurity". 
FIGURE 2

"FOOD INSECURITY" DATA, TREND AND CYCLE

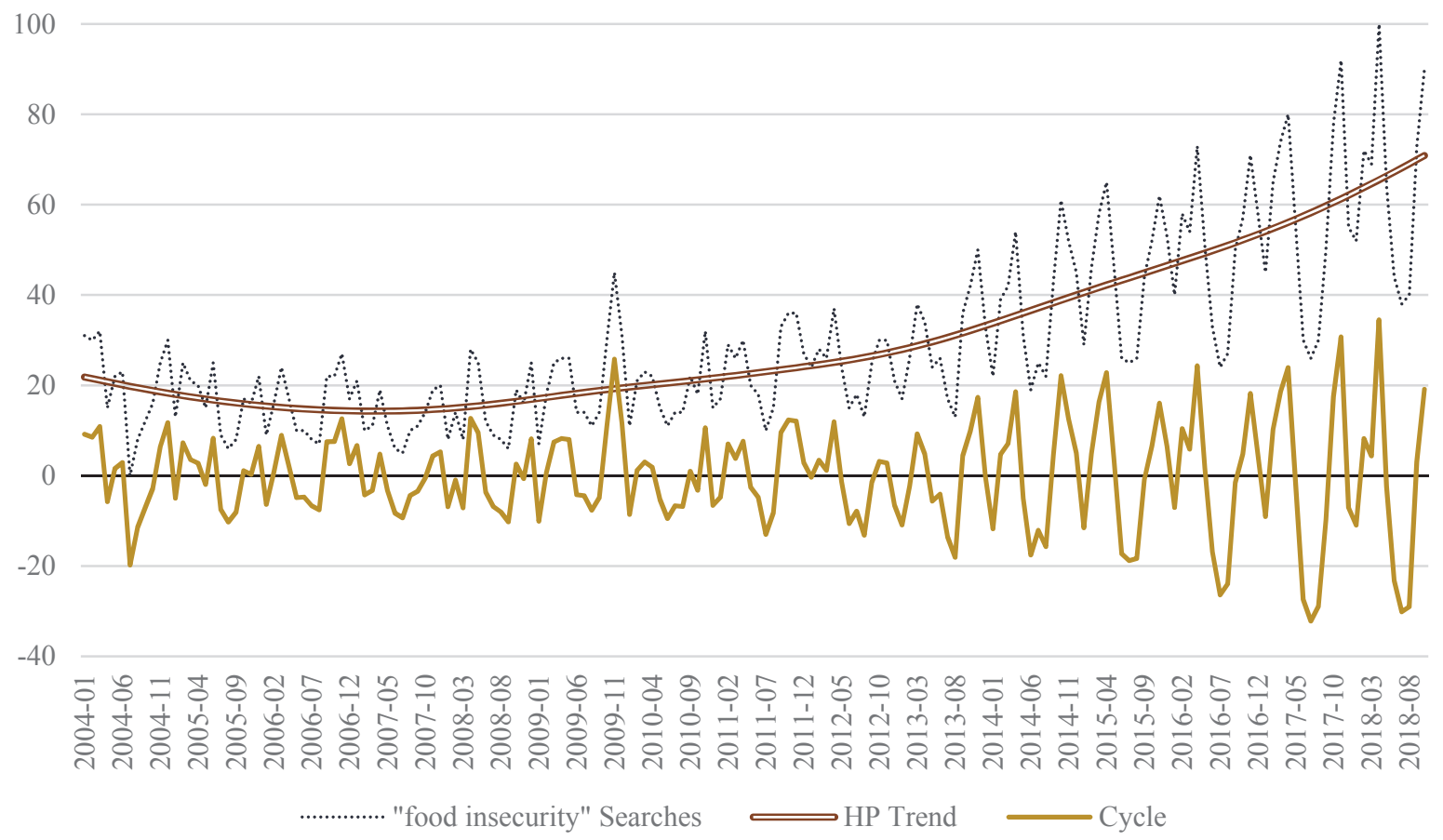

We produce multiple short-term cycles (one for each word/phrase) which we then combine into a single measure by applying numerical optimization. Using Excel Solver, a new cycle series is created which maximizes the sum of the squared correlations between itself and each keyword cycle. ${ }^{3}$ This is the 'hunger interest index' (HII) - a 'common cycle' reflecting general interest in hunger-related social business marketing messages as measured by public internet searches. The correlations between the HII and each of its component cycles can be found in table 1. 
TABLE 1

COMMON CYCLE (HII) \& INDIVIDUAL CYCLE CORRELATION

\begin{tabular}{|l|c|}
\hline Keywords & $\begin{array}{c}\text { Common Cycle (HII) \& } \\
\text { Individual Cycle Correlation }\end{array}$ \\
\hline social impact & 0.879 \\
\hline family farms & 0.103 \\
\hline sustainable agriculture & 0.768 \\
\hline local communities & 0.547 \\
\hline non gmo & 0.392 \\
\hline organic ingredients & 0.426 \\
\hline local farmers & -0.091 \\
\hline food system & 0.828 \\
\hline certified organic & 0.412 \\
\hline natural and organic & 0.566 \\
\hline organic food & 0.629 \\
\hline organic produce & 0.537 \\
\hline local agriculture & 0.437 \\
\hline sustainable farms & 0.315 \\
\hline sustainable food & 0.778 \\
\hline food insecurity & 0.754 \\
\hline food security & 0.628 \\
\hline positive social change & 0.445 \\
\hline food desert & 0.782 \\
\hline
\end{tabular}

We want to compare the HII to a measure of overall economic performance. We created a second series to represent the monthly state of the economy using data from the Federal Reserve Bank of St. Louis Economic Research data portal (FRED). All data is monthly, seasonally-unadjusted data covering the same time period, 2004-2018. We use a similar approach to the one used for the HII: first apply the HP filter to each individual series to identify a long term trend, then extract the short-term cycle for each by subtracting the HP trend from the original data, and finally use Excel Solver to create a new series which maximizes the sum of squared correlations between itself and each individual cycles. ${ }^{4} \mathrm{~A}$ description of the seven different types of economic data, and their correlation with the economic common cycle can be found in table 2 . Because this index is positively correlated with inflation and unemployment (economic 'bads') and negatively correlated with hourly wage increases, we name this the 'economic misery index' (EMI). 
TABLE 2

COMMON CYCLE (EMI) \& INDIVIDUAL CYCLE CORRELATION

\begin{tabular}{|l|c|}
\hline Economic Data & $\begin{array}{c}\text { Common Cycle (EMI) \& Individual } \\
\text { Cycle Correlation }\end{array}$ \\
\hline Civilian Unemployment Rate, Percent & 0.267 \\
\hline $\begin{array}{l}\text { Consumer Price Index for All Urban Consumers: All Items, } \\
\text { Percent Change }\end{array}$ & 0.766 \\
\hline Effective Federal Funds Rate, Percent & 0.186 \\
\hline Monthly Supply of Houses in the United States & -0.770 \\
\hline $\begin{array}{l}\text { Trade Weighted U.S. Dollar Index: Broad, Change, Index } \\
\text { Jan 1997=100 }\end{array}$ & -0.585 \\
\hline $\begin{array}{l}\text { S\&P/Case-Shiller U.S. National Home Price Index, Change, } \\
\text { Index Jan 2000=100 }\end{array}$ & 0.688 \\
\hline $\begin{array}{l}\text { Crude Oil Prices: West Texas Intermediate (WTI) - } \\
\text { Cushing, Oklahoma, Change, Dollars per Barrel }\end{array}$ & 0.742 \\
\hline $\begin{array}{l}\text { Hourly Earnings: Manufacturing for the United States, } \\
\text { Change, Index 2015=100 }\end{array}$ & -0.282 \\
\hline
\end{tabular}

Figure 3 shows the HII and the EMI together. These two series have a fairly low, albeit statistically significant ${ }^{5}$, correlation (equal to 0.226 ) when the entire series is taken into account. Obvious patterns are more apparent in some periods than others. Figure 4 measures the correlation between the HII and EMI in each period over the previous 24 months. A simple statistical test of significance ${ }^{6}$ suggests a fairly strong relationship in 3 particular periods 5/2005-9/2008, 8/2009-7/2012 and 11/2013-7/2016. We suspect that these are the periods where a downturn in the economy is the key factor driving interest in food and hunger-related issues.

FIGURE 3

THE HII AND THE EMI

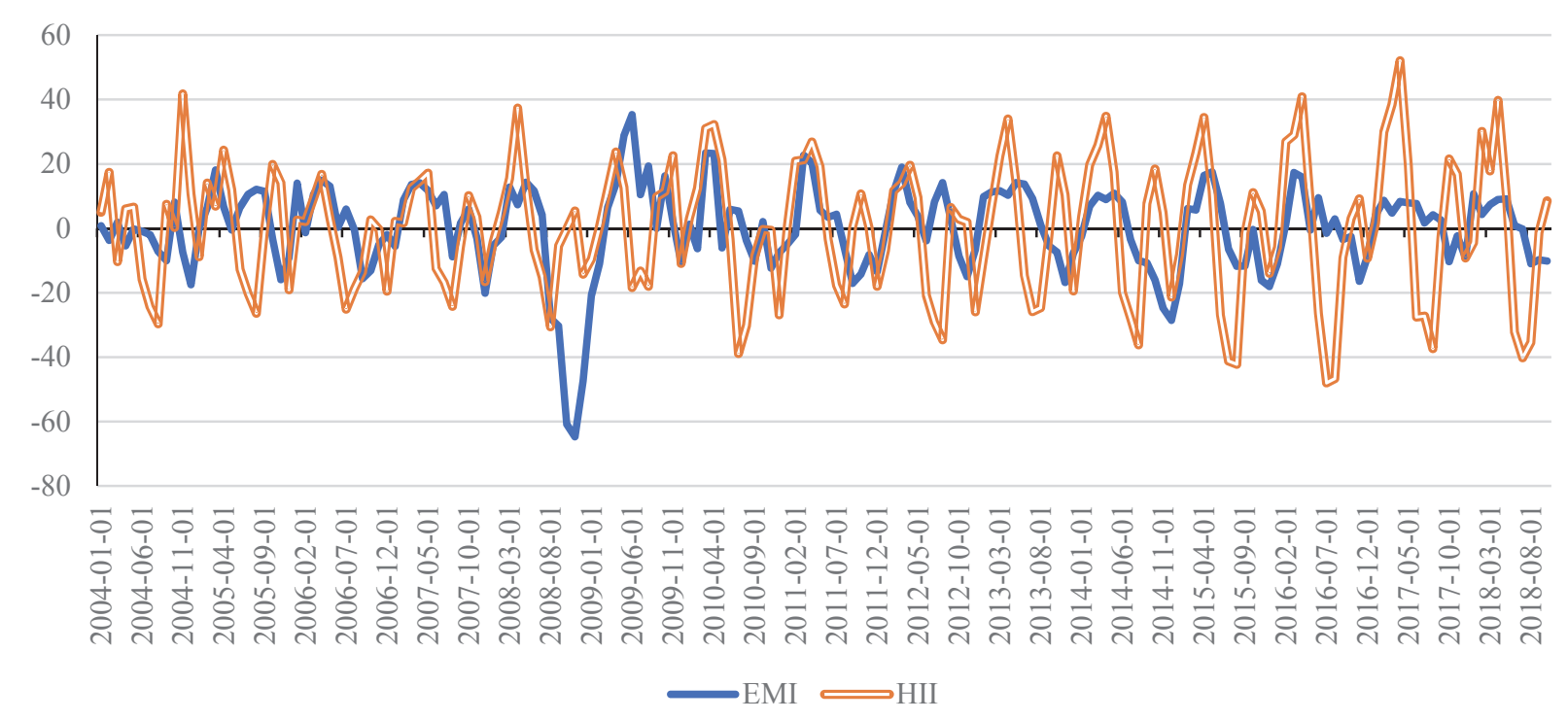

32 Journal of Applied Business and Economics Vol. 21(7) 2019 
FIGURE 4

CORRELATIONS BETWEEN THE EMI AND HII FOR THE PREVIOUS 24 MONTHS

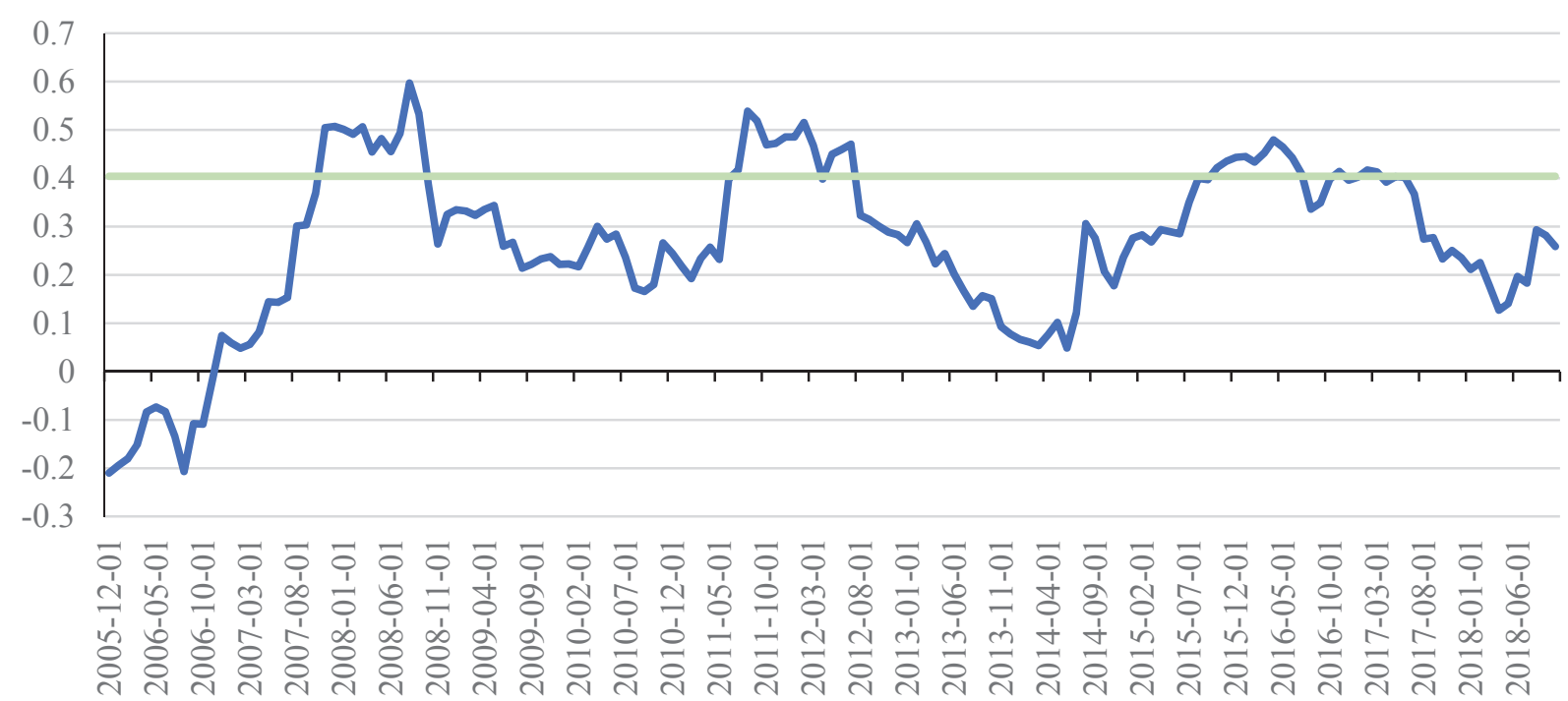

We can drill down into the index components to see how the two indices relate to each other's components. Table 3 shows the correlations between the EMI, the HII and each other's component cycles for the entire sample period. Any correlation above approximately 0.148 in absolute value is deemed statistically non-zero according to a simple statistical test ${ }^{7}$. The strongest correlation between the HII and the individual economic cycles is with the inflation rate as measured by the consumer price index. A rise in the inflation rate is positively correlated with an increase in hunger interest. Interestingly, there is a strong correlation between the EMI and keyword searches for "local farmers", "certified organic", "organic food", "organic produce" and "non gmo". This is a mystery if people are shopping online as these foods tend to be more expensive.

TABLE 3

CORRELATIONS

\begin{tabular}{|c|c|c|c|}
\hline & & EMI & $H I I$ \\
\hline \multirow{8}{*}{ 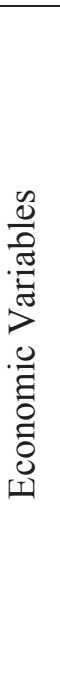 } & Civilian Unemployment Rate, Percent & 0.292 & -0.140 \\
\hline & $\begin{array}{l}\text { Consumer Price Index for All Urban } \\
\text { Consumers: All Items, Percent Change }\end{array}$ & 0.762 & 0.245 \\
\hline & Effective Federal Funds Rate, Percent & 0.179 & -0.070 \\
\hline & $\begin{array}{l}\text { Monthly Supply of Houses in the United } \\
\text { States }\end{array}$ & -0.775 & -0.225 \\
\hline & $\begin{array}{l}\text { Trade Weighted U.S. Dollar Index: Broad, } \\
\text { Change, Index Jan } 1997=100\end{array}$ & -0.563 & -0.137 \\
\hline & $\begin{array}{l}\text { S\&P/Case-Shiller U.S. National Home Price } \\
\text { Index, Change, Index Jan } 2000=100\end{array}$ & 0.693 & 0.192 \\
\hline & $\begin{array}{l}\text { Crude Oil Prices: West Texas Intermediate } \\
\text { (WTI) - Cushing, Oklahoma, Change, } \\
\text { Dollars per Barrel }\end{array}$ & 0.720 & 0.115 \\
\hline & $\begin{array}{l}\text { Hourly Earnings: Manufacturing for the } \\
\text { United States, Change, Index } 2015=100\end{array}$ & -0.282 & -0.050 \\
\hline
\end{tabular}




\begin{tabular}{|c|c|c|c|}
\hline & & $E M I$ & $H I I$ \\
\hline \multirow{19}{*}{ 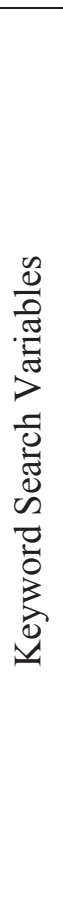 } & social impact & -0.005 & 0.879 \\
\hline & family farms & -0.138 & 0.103 \\
\hline & sustainable agriculture & 0.037 & 0.768 \\
\hline & local communities & 0.027 & 0.547 \\
\hline & non gmo & 0.317 & 0.392 \\
\hline & organic ingredients & 0.256 & 0.426 \\
\hline & local farmers & 0.437 & -0.091 \\
\hline & food system & 0.244 & 0.828 \\
\hline & certified organic & 0.418 & 0.412 \\
\hline & natural and organic & 0.228 & 0.566 \\
\hline & organic food & 0.451 & 0.629 \\
\hline & organic produce & 0.367 & 0.537 \\
\hline & local agriculture & 0.150 & 0.437 \\
\hline & sustainable farms & 0.123 & 0.315 \\
\hline & sustainable food & 0.183 & 0.778 \\
\hline & food insecurity & -0.011 & 0.754 \\
\hline & food security & 0.062 & 0.628 \\
\hline & positive social change & -0.078 & 0.445 \\
\hline & food desert & 0.033 & 0.783 \\
\hline
\end{tabular}

To isolate interest in hunger relief, which is important for estimating consumer demand for a hungerbased business, we create an index using keyword searches for "food stamps", "food bank", "free school lunch", and "food pantry". We extract a short term cycle from each then compile a 'common cycle' index in the same fashion as the HII. We refer to this index as the 'food bank index' (FBI). Correlations between the EMI, the HII and the FBI appear in table 4. Oddly, there is a negative correlation between the FBI (and its components) with the EMI: as the EMI rises, the economy takes a downturn and searches for things like "food banks" and "food pantry" (strong drivers in the FBI) tend to fall. This appears unexpected at first if we assume the motivation for searching for things like "food banks" is because people need food, which we expect more of during an economic slump. However, an alternative reason for looking up food banks and food pantries is for donation purposes - to make a contribution. We expect contribution efforts to fall off as the EMI rises.

It may be useful to isolate interest in general sentiments of charity and giving as a means to extract the 'contribution' effect from the FBI. We create one last index of the same style as the HII and FBI using keyword searches for "donation", "giving", "charity" and "volunteering". We call this the "volunteer interest index' (or VII). Correlations between the EMI, HII and VII appear in table 4. Note that the VII is positively correlated with "food bank" and "food pantry". The sign of the correlation with the EMI is negative: as the economy takes a downturn, searches for things like "giving" and "charity" fall. This is expected as philanthropic individuals become cash-strapped when the economy struggles. Note the VII is weakly and negatively correlated with the "food stamps" and "free school lunch" components of the FBI. This is also expected as both types of programs do not lend themselves to charitable giving. In the end, for practical decision-making purposes, hunger-related social enterprises can rely on a food-specific metric like the FBI knowing that largely reflects charitable sentiments. 
TABLE 4

CORRELATIONS

\begin{tabular}{lllll}
\hline & $E M I$ & $H I I$ & $F B I$ & $V I I$ \\
\hline food bank & -0.552 & -0.004 & 0.916 & 0.704 \\
food pantry & -0.585 & -0.186 & 0.949 & 0.510 \\
food stamps & -0.124 & -0.206 & 0.358 & -0.011 \\
free school lunch & -0.115 & -0.459 & 0.093 & -0.199 \\
FBI & -0.590 & -0.147 & 1.000 & 0.582 \\
donation & -0.120 & 0.033 & 0.277 & 0.746 \\
giving & -0.386 & 0.267 & 0.637 & 0.679 \\
charity & -0.265 & 0.236 & 0.458 & 0.860 \\
volunteering & -0.158 & 0.359 & 0.421 & 0.772 \\
VII & -0.304 & 0.281 & 0.582 & 1.000 \\
\hline
\end{tabular}

\section{DISCUSSION AND APPLICATION}

We can use the results from the previous section to address some common decision-making problems for social enterprises. We take a theoretical approach for this. All of the examples that follow focus on optimal timing.

\section{When to Launch and Market a Hunger-related Social Enterprise}

Figure 5 shows the monthly average for the EMI and HII indices. The figure suggests that although the HII cycle hits a peak in April, the EMI tends to be high at this time. Since it is not ideal to begin a new venture at a time of economic hardship, when customer spending is likely to be low, a social entrepreneur may wish to wait until the HII hits its second peak in October-November to launch. At this time, economic misery will be fairly low and sales may be relatively higher. To take advantage of consumer interest in the marketing messages of hunger-related ventures, a social business may wish to market more in March-April and October-November. At these times, public interest is high and the capture associated with marketing efforts will likely be larger. These recommendations hold all else constant; there are surely other factors a business will want to account for in practice. 
FIGURE 5

\section{MONTHLY AVERAGE EMI AND HII}

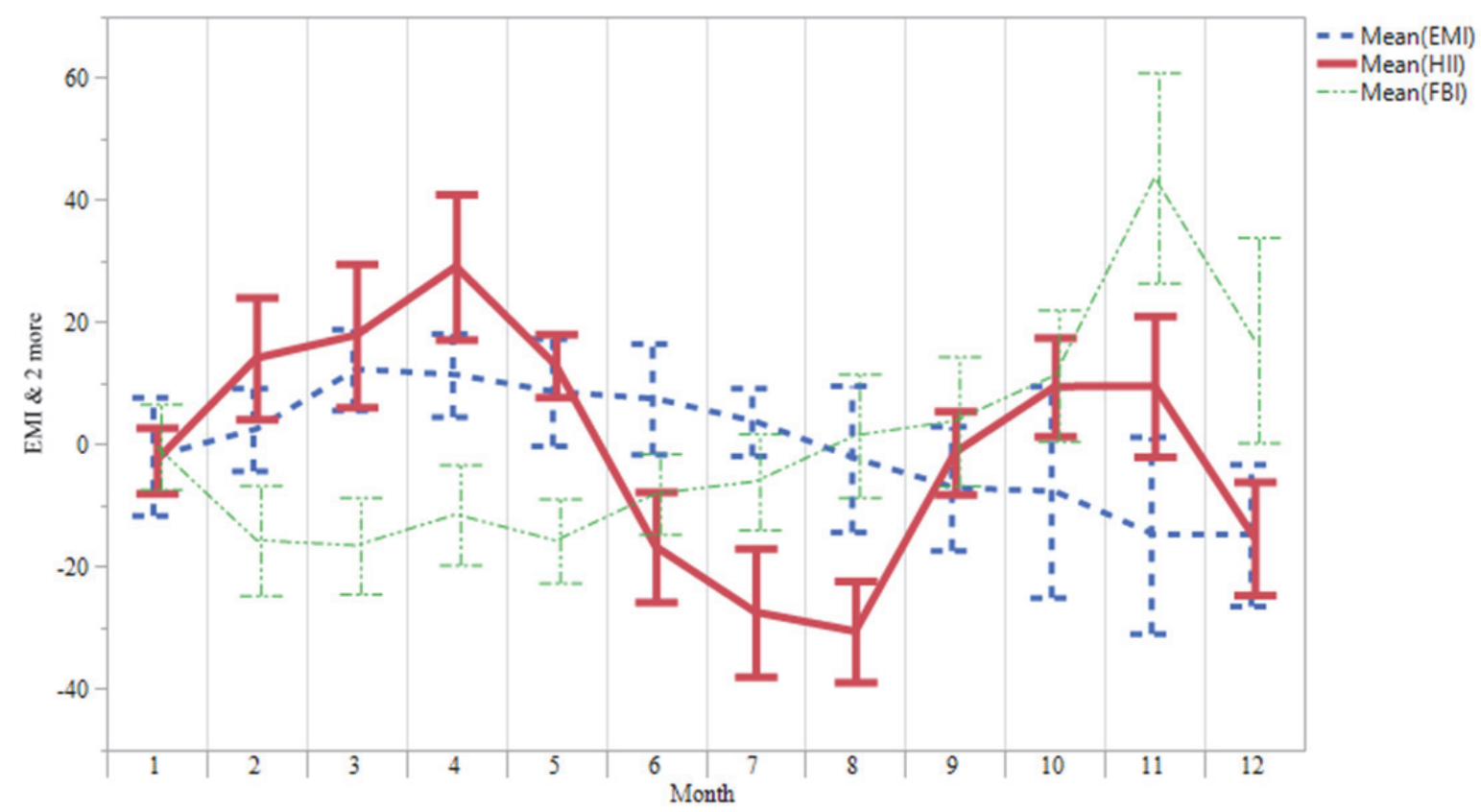

Each error bar is constructed using 1 standard deviation from the mean.

\section{Making Sales Versus Contributing to Social Initiatives}

The pattern which appears in figure 5 also gives hints as to the timing of sales versus the need a hunger-related business faces when meeting its mission. A social business's profits will likely depend on both marketing factors (related to the HII) and economic factors (related to the EMI). Incoming revenue may be highest in October-November, with somewhat lower revenues in March-April due to a dwindling economy. Need for food will depend on aggregate economic factors; it appears that March-June on average is a time of greater need. Charitable food-related interests (related to the FBI) are highest in the holiday months (November-December) suggesting a lack of public efforts when need is greatest. When it comes to optimizing, figure 5 suggests that a hunger-related social business may experience an intermediate income stream from January-May, followed by a slim income stream until August, after which their income stream will pick up through the end of the year (until December). When distributing profits towards meeting its mission, that same social business may find it can meet the greatest needs by focusing its spending on February-June, then allow charities to dominate relief efforts from August to December. As before, these recommendations hold all else constant.

\section{CONCLUSIONS, LIMITATIONS AND FUTURE RESEARCH}

If social businesses can take root, they can aid in meeting the United Nation's Sustainable Development Goals. In the case of hunger, we analyze publicly available Google search data alongside economic data to produce tools to aid in decision-making for these sorts of firms. By following consumer interest, social businesses can gain insight on when to launch, when to advertise and when to spend their profits on their mission. Accounting for upswings and downturns in the economy helps refine the planning.

This research is limited on several dimensions. Only a limited number of words are used, some of which may not be relevant to a particular sort of business. Individual ventures may wish to tailor make their own indices including search terms that are relevant to the specific wordings in their missions. 
Further, we have not quantified the impact that social business can have on an SDG. As the SDGs are still fairly new, and social business is only recently in vogue, this is a topic for future research.

\section{ENDNOTES}

1. *

2. The text analytics features in JMP Pro, a SAS statistical software package, was used to identify highfrequency terms.

3. The common cycle was rescaled to have a mean of zero. This is only for display purposes and does not affect the implications of the study.

4. The economic index is rescaled to have a mean of zero. This is for display purposes only and does not affect the implications of the study.

5. For this, we use a very simplistic statistical test. We identify a critical value above which we can reject a null of "no correlation" at the $95 \%$ confidence level. There are 178 periods in our sample (amounting to 176 degrees of freedom). We identify a critical value of approximately 0.148 using a Pearson's correlation table.

6. For this, we identify a critical value above which we can reject the null of "no correlation" at the $95 \%$ confidence level. Using 24 periods (amounting to 22 degrees of freedom), we identify a critical value of 0.404 using a Pearson's correlation table.

7. We identify a critical value above which we can reject a null of "no correlation" at the $95 \%$ confidence level. There are 178 periods in our sample (amounting to 176 degrees of freedom). We identify a critical value of approximately 0.148 using a Pearson's correlation table.

\section{REFERENCES}

About B Corps. (2018, December 15). Certified B Corporation. Retrieved from https://bcorporation.net/about-b-corps

Abreu, M., Laureano, R., da Silva, R., Dionísio, P., \& Faridah Syed Alwi, S. (2013). Managing volunteering behavior: The drivers of donations practices in religious and secular organizations. Available at SSRN 2380085.

Balch, O. (2017, November). Make money while doing good. Raconteur. Retrieved from https://www.raconteur.net/business-innovation/make-money-while-doing-good.

Bekkers, R., \& Wiepking, P. (2011). A literature review of empirical studies of philanthropy: Eight mechanisms that drive charitable giving. Nonprofit and Voluntary Sector Quarterly, 40(5), 924 973.

Birkenmaier, J., Huang, J., \& Kim, Y. (2016). Food insecurity and financial access during an economic recession: Evidence from the 2008 SIPP. Journal of Poverty, 20(2), 194-213.

Cappellari, L., Ghinetti, P., \& Turati, G. (2011). On time and money donations. The Journal of SocioEconomics, 40(6), 853-867.

Croson, R., Handy, F., \& Shang, J. (2009) Keeping up with the Joneses: The relationship of perceived descriptive social norms, social information, and charitable giving. Nonprofit Management and Leadership, 19(4), 467-489.

De Abreu, M. E., Laureano, R. M., da Silva, R. V., \& Dionísio, P. (2015). Volunteerism, compassion and religiosity as drivers of donations practices. International Journal of Nonprofit and Voluntary Sector Marketing, 20(3), 256-276.

Dilmaghani, M. (2019). The racial 'digital divide' in the predictive power of Google trends data for forecasting the unemployment rate. Journal of Economic and Social Measurement, (Preprint), 124.

Einof, C.J. (2011). Gender Differences in the correlates of volunteering and charitable giving. Nonprofit and Voluntary Sector Quarterly, 40(6), 1092-1112.

Facts About Hunger and Poverty in America. (2019, February 27). Feeding America. Retrieved from https://www.feedingamerica.org/hunger-in-america/facts 
Farhat, D., \& Viitanen, T. (2017). Business 'Psych'cles: A close look at mental health and state-level economic performance using Google search data. Review of Economic Analysis, 9(2), 107-125.

Farhat, D. (2017). Awareness of sexually transmitted disease and economic misfortune using search engine query data. International Journal of Business and Economics, 16(1), 101-108.

Flatters, P., \& Willmott, M. (2009). Understanding the post-recession consumer. Harvard Business Review, 87(7/8), 106-112.

Ginsberg, J., Mohebbi, M. H., Patel, R. S., Brammer, L., Smolinski, M. S., \& Brilliant, L. (2009). Detecting influenza epidemics using search engine query data. Nature, 457, 1-20. doi:10.1038/nature07634

Kang, M., Zhong, H., He, J., Rutherford, S., \& Yang, F. (2013). Using Google trends for influenza surveillance in South China. PloS one, 8(1), e55205.

Kim, S., Karlesky, M. J., Myers, C. G., \& Schifeling, T. (2016). Why companies are becoming B corporations. Harvard Business Review, 17.

Mansoor, D., \& Jalal, A. (2011). The global business crisis and consumer behavior: Kingdom of Bahrain as a case study. International Journal of Business and Management, 6(1), 104-115.

Mesch, D. J., Brown, M. S., Moore, Z. I., \& Hayat, A. D. (2011). Gender differences in charitable giving. International Journal of Nonprofit and Voluntary Sector Marketing, 16(4), 342-355.

Mission. (2019, March 8). Lycka. Retrieved from https://www.lycka.bio/pages/mission1\#s-e1290403367d-43d7-b5b6-572e349fd89d

Nuti, S. V., Wayda, B., Ranasinghe, I., Wang, S., Dreyer, R. P., Chen, S. I., \& Murugiah, K. (2014). The use of Google Trends in health care research: a systematic review. PloS one, 9(10), e109583.

Osborn, D., Cutter, A., \& Ullah, F. (2015). Universal sustainable development goals. Understanding the Transformational Challenge for Developed Countries.

Posnett, J., \& Sandler, T. (1989). Demand for charity donations in private non-profit markets: The case of the UK. Journal of Public Economics, 40(2), 187-200.

Saatci, E. Y., \& Urper, C. (2013). Corporate social responsibility versus social business. Journal of Economics, Business and Management, 1(1), 62-65.

Sharkey, J. R., Dean, W. R., \& Nalty, C. C. (2013). Child hunger and the protective effects of Supplemental Nutrition Assistance Program (SNAP) and alternative food sources among Mexican-origin families in Texas border colonias. BMC Pediatrics, 13(1), 143.

Smith, J. R., \& McSweeney, A. (2007). Charitable giving: The effectiveness of a revised theory of planned behaviour model in predicting donating intentions and behaviour. Journal of Community \& Applied Social Psychology, 17(5), 363-386.

Trussel, J. M., \& Parsons, L. M. (2007). Financial reporting factors affecting donations to charitable organizations. Advances in Accounting, 23, 263-285.

United Nations. (2015). The Sustainable Development Agenda: Goal 2 Zero Hunger. Retrieved from https://www.un.org/sustainabledevelopment/hunger/

United Nations. (2018). The Sustainable Development Goals Report. Retrieved from https://unstats.un.org/sdgs/report/2018/overview/

Von Braun, J. (2008). Food and financial crises: Implications for agriculture and the poor (Vol. 20). International Food Policy Research Institute.

Zhou, X., Ye, J., \& Feng, Y. (2011). Tuberculosis surveillance by analyzing Google trends. IEEE Transactions on Biomedical Engineering, 58(8), 2247-2254. 